\title{
The Reforms and Explorations in Law-Related Education of Normal College Students
}

\author{
Lei Wang ${ }^{1, a}$ \\ ${ }^{1}$ Feixian School, Linyi University, Feixian, Shandong, P.R.China \\ alydxmfl@126.com
}

\begin{abstract}
To strengthen the ideological moral education and lawrelated education of adolescents for the whole Party and society, especially school. Because of the Lack of the lawrelated education, the normal college hasn't finished the task of cultivating student's law ruling concept well enough. The lack of appropriate law-related education leads to student's lack of law ruling concept.
\end{abstract}

Keywords: Normal students; Law-related education; Measures

\section{Introduction}

As the old saying goes: the nation will be strengthened if the law enforcement conducts lawfully, , while be weakened when the law enforcement conducts lawlessly.

School is obliged to strengthen the ideological moral education and law-related education of adolescents. Due to some negative social atmosphere, along with the law-related education of school's becoming a mere formality, uncivilized even illegal behaviors happens now and then on campus, not only students, even school and teachers also has became violators. Its deep cause is easy to find, normal school puts little or no emphasis on the law-related education of the students, who are would-be teachers after graduation. The normal school students' inactive law ruling concept and school's lack of law-related education are " original sins" that caused the above-mentioned problems.

\section{The present state of the legal consciousness of primary and middle school students and teachers in region}

At this stage, along with the reform\& opening and the development of market economy, the economic basis and superstructure has been transformed a lot correspondingly, the economic elements and benefits, the social lifestyle, the form of social organization, the employment posts and situations, people's thoughts and orientation of values, etc. all of above-mentioned aspects has been diversified greatly. Influenced by the diversification, teachers become confused, some of them are not competent to act the role of cultivating talents because of their lack of corresponding ideological quality and professional moral quality. The professional characteristics of teachers make greater demands on their legal consciousness than on average citizens. However, now there are quite a lot of schools lack the consciousness of profession-related laws, let alone teachers, who have little knowledge of such laws relevant to their professions as Regulation of Dealing with Students' Injury Accident, General Principles of Civil Law of People's Republic of China, Juvenile Protection Law of People's Republic of China, etc. let alone ruling school or teaching in accordance with law. There are two chief reasons: one is that normal schools hasn't put emphasis on law-related education of students; the other is that the students lack legal consciousness, they will not move with times to notice new regulations, let alone directing their own educating practices in accordance with law. They can't distinguish between rights and obligations, confuse law with morality, and lack separate laws. We usually describe these people with the sentence: The ignorant person fears nothing. The phenomenon doesn't comply with the strategy of ruling our country by law.

\section{The necessity of defending both teacher and student' $s$ rights, to protect and develop oneself}

There is always a confliction between traditional culture and modern legal idea in Yimeng Mountain Area, which is deeply influenced by the traditional culture. Plenty of unnecessary damages has been caused because we has always been overemphasizing the respect for teachers and ignoring the modern rule of law. For one thing, many parents of primary and middle school students have little knowledge of protecting kid's' personal rights, influenced by the traditional wisdom of "the less trouble the better" ,majority of them choose to swallow the insult after their kids subjected to physical punishment or personal injury, which just indulge the injury even illegal acts. For another, under the disguise of caring and educating, some teachers are still following the example of traditional private school teachers, scold even beat students, and has caused great damage to students physically and mentally[1]. Besides, teacher also suffers from school's poor management, their lack of awareness of protecting their personal rights also indulge the flourish of dictation and corruption in school.

Actually, both the law and morality are tools to behave people. The law plays its compulsive role externally, while the morality plays its role internally[2]. To regulate the 
behaviors of school faculty, both the legal authority and socialist ethics are needed. In ruling school, law and morality are built on each other, both are necessary for the construction of school, especially now, with the further development of reforms and opening up, the socialist market economy continues to improve, which is proved by plenty of educational theories and practices from home and aboard. Ruling school by law means to enhance law-related education among school faculty, to educate them to learn, understand and apply law, so as to build and improve socialist legal civilization[3]. Ruling school by morality means to educate school faculty the ideas of serving people, and carry out patriotism education, socialist ideological education, social ethics education, professional ethics education and family virtue education among them frequently.

The fundamental duty of a teacher is teaching and cultivating. A qualified teacher is not a simple tool of teaching, but a spreader of knowledge, a mentor of students in daily life and leader of students in morality. Upholding the rule of law helps to keep the absolute dignity of teachers, to defend both the students and teachers' personal rights. To reinforce the law-related education, bring primary and middle school students a pleasant studying atmosphere, make the primary and middle school teachers the moral and legal guides, is the urgent demand of training qualified teachers, the important means to defend teachers and students' rights, shows the progress we have made in building legal society in new era, and furthermore helps to advance the modern civilization[4].

\section{The current analysis of legal education among normal students in college and solutions to form atmosphere of law-related education}

The current law-related education consists of two forms: classroom teaching and extracurricular activity, while there are some serious problems in both kind of forms[5]. The extracurricular activity usually holds once a semester and only for a short period of time, the contents has always been a formal report on law-related education, which is just formal universe education and warning on laws, of little use in fostering students' legal consciousness. While for classroom teaching, the amount of time spent on legal education is short, and the legal contents discussed in classroom is usually boring, abstract, empty and theoretical, can't arouse students' interests, so classroom teaching hasn't played its role well enough.

In view of such kind of situation, we put up some solutions after survey: regulate students and teachers' behaviors through fostering legal consciousness and cultivate the custom to abide by law, and put emphasis on the actual effect of educational model.

4.1. keep the new normal of making legal reports during extracurricular activity. On the premise of popularizing basic knowledge of law, considering the age and profession traits of students, we should make the contents more pointed, profound, easy to understand and conforms to the times. The bulletin board should be filled with lively cases that will spread legal knowledge to people, to attract them, to impress them. School website should try her best to make the legal column more attractive and participatory, to make the legal competitions more popular through multi-media, to build a interesting atmosphere for legal studying. Meanwhile, we should increase students' participation in making legal columns and enhance their ability in organizing these legal activities, it will help them to promote their own legal consciousness and educate their students correctly in the near future, then hand the legal consciousness down from one generation to another.

4.2. Create new classroom normal of promoting students' legal spirit effectively. It enable students to study further and well, helps to cultivate their law ruling concept. With the aim of inherit the legal concept at work, it advocates reform on the teaching model boldly, and takes the example of modern media on legal information and modern information technology to make a class filled with the legal cases happened in reality[6]. Students can be organized to simulate the juror or lawyers in courts to defend the new model of teaching, which will help to make students to learn laws more actively and accustom them to laws much better in activities, and avoids the impossibility of organizing teaching activities on law-related education, of which the contents is somewhat boring and abstract. Combined with cases happened in real life will help to arouse students' interests in laws when in class, and the interest will propel them to preview before class and performs well in class. Apart from the reform of teaching model, we should also pay attention to foster people's foresight in the dynamic of legal concept, the imperfect regulations will become perfect one day, the unborn ones will be born as well. These blindness or imperfection of laws ought not to weaken the authority of laws, or students' respect for law, normal students should always equip themselves with noble morality and civilized manners even when the legal system is a little far from perfect, this is what makes them different from average persons.

\section{The reform and model innovation of law-related education of normal students in college}

With the aim to change students from "I can learn" to "I ' $\mathrm{d}$ like to learn", then make them master teaching activity well, the new teaching model will help to cultivate students' legal concept and spirit, and facilitate them to influence students and other people at work in the future. The main reforms on teaching model as follows:

5.1. Fill class with real-world cases and practical legal information. Combine activity as Today's Law with 
discussion of theory through real-world cases, with the improvement of practical legal skills.

5.2. Set up moot court in classroom, motivate students to take part in from trail to defense.

5.3. Carry out competitions in promotional videos on rule of law, the contents of video should embody the mutual help of information technology and rule of law.

5.4. Organize essay activities with underlying theme "under the rule of law, what should I do in daily life", and address the topic of "life under the rule of law".

5.5. Competitions in laws such as Regulation of Dealing with Students' Injury Accident, General Principles of Civil Law of People's Republic of China, Juvenile Protection Law of People's Republic of China, etc.

5.6. Foster normal students' foresight in dynamics of legal thinking, and unit their legal consciousness with professional ethics.

\section{CONCLUSIONS}

All of the above-mentioned combinations of daily behaviors with the rule of law will help students to learn the role legal spirit plays in guiding daily behaviors [7]. Our duty is to change the abstract laws into lively ones, to bring them into our real life. Through introducing relevant legal programs into classroom, we could improve the contents to be taught, and try our best to emphasize on law and morality, prevention and protection, the population of knowledge and case study. We should help students to think about problems in two angles in their making and addressing the cases, now being students, while later will be teachers, they ought to know how to implement law-related education on students. Try to use the descriptions or story easy for students to understand as much as possible in law-related education, generate realistic circumstances through cartoons or microfilms, and design many interactive sessions carefully to inspire students to think independently, to arouse their passion. The reform combines abstract laws with lively cases in real life, teaches students how to act correctly under the rule of law and benefits them a lot.
Reform demands courage, but demands more test of practice. While in the reform of law-related education, apart from being investigated and tested by school, we should also notice students' feedback and the actual effect of reform, to improve the inadequacy and correct mistakes, and then propel the qualified model to teacher training. With the form of new normal of law-related education, and make it the core strength in teacher training, in this way the education we have taken part in will be able to make contributions to the rule of law.

\section{Acknowledgments}

The authors wish to give their sincere thanks to the editor and the anonymous referees for their valuable suggestions and helpful comments which improved the presentation of the paper.

\section{References}

[1] Kuang Hongbo, The Rule of Law in College and the Protection of Student's Rights [D].North China University of Technology,2011

[2] Feng Xiaoka ,The Study on Modern Ideological and Political Education in Colleges From the Side of Law[D]. Hubei University of Technology,2011

[3] Zhang Mingxin, Reflection on Modern Law Popularizing Education of China[J]10 Law Journal,2009

[4] Geng Qiulan, The Study on the combination of legal education and moral education in college[D].Wuhan Textile University,2011.

[5] Lou Shujuan, the Study of Educational Legal Institutions in Moral Education in College[D].Shandong Normal University,2002.

[6] Zhang Jianzhi, The Discussion of Legal Problems in Ruling the School by Law[D]. Shandong Normal University,2002.

[7] Policies \& Regulations Department, Advance the Reform, Research Policy, Strengthen the Rule of Law[N].Education of China,2011. 